\title{
PREVALENCE OF HUMAN PAPILLOMA VIRUS IN A TERTIARY CARE CENTRE IN CENTRAL INDIA USING p16 IMMUNOEXPRESSION AS A SURROGATE MARKER
}

\author{
Priyanka Yadav ${ }^{1}$, Puneet Tandon ${ }^{2}$
}

1MD Candidate, Department of Pathology, Gandhi Medical College, Bhopal, Madhya Pradesh, India.

${ }_{2}^{2}$ MD, Department of Pathology, Gandhi Medical College, Bhopal, Madhya Pradesh, India.

\begin{abstract}
BACKGROUND
ABSTRACT

High risk Human Papilloma Virus (HR-HPV) has now emerged as one of the major etiological factors in oral and oropharyngeal cancer. Knowing HPV status is crucial as it has a significant impact on therapeutic front as well as on prognosis. As p16 immunoexpression can serve as surrogate marker for HR-HPV infection, in the current study we used p16 immunoexpression to determine the prevalence of HPV in a tertiary care centre in Central India.
\end{abstract}

\section{MATERIALS AND METHODS}

This is hospital based cross sectional study conducted in oral biopsy tissues (for neoplastic lesions) received for histopathological evaluation over a period of one and half years. The sections were processed for H \& E staining, and 112 cases were chosen for immunohistochemical study. The data was analysed by chi-square and Z-tests using software SPSS.

\section{RESULTS}

Positive diffuse p16 immunoexpression was present in $23.2 \%$ of the cases irrespective of histological type/grade of the lesion. We found significant correlation between degree of dysplasia and p16 immunoexpression with $16.7 \%$ of cases showing positivity in OIN I cases as compared to $25 \%$ in OIN II and $77.8 \%$ in OIN III. Poorly differentiated tumours had high proportion of cases with positive p16 immunoexpression (75\%) compared to well differentiated (29.3\%) and moderately differentiated squamous cell carcinomas (35.5\%). Additionally, higher proportion of female patients (43.8\%) had diffuse p16 positivity than males (17\%).

\section{CONCLUSION}

We conclude that HPV prevalence in our tertiary care centre is approximately $23.2 \%$. This subset of cases was found to be associated more with oropharyngeal lesions and was present in higher proportions in female patients. Apart from serving as a surrogate marker for HR-HPV, p16 immunoexpression also correlates with the degree of dysplasia in oral and oropharyngeal lesions.

\section{KEY WORDS}

Human Papilloma Virus, p16, Oral Squamous Oral Carcinoma, Oropharyngeal Squamous Cell Carcinoma, Dysplasia HOW TO CITE THIS ARTICLE: Yadav P, Tandon P. Prevalence of human papilloma virus in a tertiary care centre in central India using p16 immunoexpression as a surrogate marker. J. Evolution Med. Dent. Sci. 2019;8(09):644-648, D0I: $10.14260 /$ jemds/2019/142

\section{BACKGROUND}

Cancers of oral cavity and oropharynx collectively contribute to substantial morbidity and mortality worldwide with highest incidence in India and Southeast Asian countries.(1) In fact, in India, $60-80 \%$ of patients present with advanced disease(2) as compared to $40 \%$ in developed countries( ${ }^{(3)}$ hence reducing the overall survival rate. Understanding the risk factors and patterns of degree of dysplasia and malignancy can help early identification and prompt treatment of patients with oral cancers. Oral and oropharyngeal cancers have a multifactorial carcinogenesis with a plethora of lifestyle and environmental factors acting as risk factors.

'Financial or Other Competing Interest': None.

Submission 23-01-2019, Peer Review 20-01-2019,

Acceptance 22-01-2019, Published 04-03-2019.

Corresponding Author:

Dr. Puneet Tandon,

Pathology Specialist, Class I,

Department of Pathology,

Gandhi Medical College,

Sultania Road, Near Hamidia Hospital,

Royal Market, Bhopal-462001,

Madhya Pradesh, India.

E-mail: drpuneettandon@yahoo.co.in

DOI: 10.14260/jemds/2019/142

Though the dominant and synergistic role of chemical toxins in tobacco and alcohol in the causation of most head and neck squamous cancers is undisputed,(4-6) but other factors appear to play a role. Chief among these is the probable pathogenic role of oncogenic HPV virus infection in the development of some head and neck cancers.(7) HPVs, especially those genotypes of known high oncogenic potential in uterine cervix and skin such as HPV 16 and 18, are found in a variable but small proportion of oral, and up to $50 \%$ of tonsillar and oropharyngeal SCCs, especially the tonsil.(8-11) After controlling for other accepted risk factors like smoking and alcohol, high-risk sexual behaviors appear to place individuals at higher risk for these HPV-associated oropharyngeal cancers. ${ }^{(12)}$

In the case of HPV positive oral cancer, inactivation of the $\mathrm{Rb}$ pathway is achieved through expression of the HPV E7 protein, which binds RB1 and abrogates the requirement for p16 silencing. RB1 inhibits transcription of p16 causing an increased immunohistochemical expression. As a result, assaying p16 protein expression in tumour cells by immunohistochemistry (IHC) is of clinical value in determining HPV status.(13) Several studies have validated high degree of association of HPV infection and p16 expression suggesting that $\mathrm{p} 16$ can be used as a surrogate marker for high risk HPV in oral squamous cell carcinomas.(14-16) 
In this study, we aimed to determine the prevalence of HPV in patients with oral and oropharyngeal carcinoma at a tertiary care hospital in Central India using p-16 as a surrogate marker of high-risk HPV infection. Additionally, association of p-16 immunoexpression with clinicopathological characteristics, namely, age, sex and histological type/grade of cancer was established.

\section{MATERIALS AND METHODS}

\section{Study Design}

A hospital based cross sectional study was conducted from $1^{\text {st }}$ March 2017 to $1^{\text {st July } 2018 .}$

\section{Cases}

In the present study, all oral biopsy tissues (For neoplastic lesions) received in the Department of Pathology for histopathological evaluation during the study duration, were included in the study. Biopsies with tissue insufficient for histopathological evaluation and autolyzed samples were excluded from the study. The study was approved by institutional Ethics Committee. A thorough history through interview, case files and information from requisition forms received in department of pathology were obtained. All the biopsy samples were processed for H\&E staining and slides were evaluated by two investigators independently. The reporting was done using Broder's grading system and WHO tumour classification.

\section{Immunohistochemistry}

112 cases were included comprising of 12 benign cases, 19 pre-malignant cases (six OIN 1, four OIN II and nine OIN III), 41 cases of WDSCC, 31 cases of MDSCC, 8 cases of PDSCC and 3 cases of Verrucous carcinoma. Of the total cases, 73 (74.5\%) cases were from the oral cavity and 25 (25.5\%) from the oropharyngeal lesion. The selected sections were mounted on poly lysine coated slides. Immunohistochemistry was performed using antibody p16 (Clone 1E12E10, Thermo Fisher Scientific, UK) as indicated on Pierce ${ }^{\mathrm{TM}}$ Peroxidase IHC Detection Kit by Thermo Fisher Scientific. Cases were classified as either positive (nuclear and cytoplasmic staining) or negative (No staining or isolated nuclear or cytoplasmic staining). The results were recorded as Index of Positivity (IP) Score and Staining Intensity according to protocol used by Dragomir et al., 2012. (17) IP score was assigned $0(<10 \%), 1(10-50 \%)$ and $2(>50 \%)$ according to the percentage of positive stained cells in 1000 counted cells in the $40 \times$ microscope field. The staining intensity was graded as follows: 0 - no staining, 1 - weak staining intensity, 2 - intermediate, and 3 - strong staining intensity. Only a score of 2 was considered as positive immunoexpression in terms of high-risk HPV association. 0 score was considered as negative (Figure 1).

\section{Statistics}

The data was analysed using appropriate statistical tests using software SPSS. The qualitative data was expressed in terms of percentages. Comparison of the qualitative variables between groups was done using the chi-square test as well as $\mathrm{Z}$ test. $\mathrm{P}$ value was considered significant if $\mathrm{p}<0.05$, and highly significant if $\mathrm{p}<0.01$. A $\mathrm{Z}$ score $>1.96$ was considered significant.

\section{RESULTS}

Irrespective of the histological type/grade and site of the lesion, $35.7 \%$ of total cases showed positive p16 immunoexpression (IP Score $1 \& 2$ ) with diffuse positivity (IP score of 2) in $23.2 \%$ of cases. Oropharyngeal lesions had higher diffuse p16 immunoexpression positive cases (28\%) compared to those of oral lesions (20.6\%) (Figure 2), however the difference was not statistically significant ( $p$ value $=0.4$ ). Results of p16 immunoexpression in terms of index of positivity and Intensity score in various histological types and grades of lesions are summarized in table $1 \& 2$. Benign cases, all of which were chronic inflammation cases, did not show any positive p16 immunoexpression. Premalignant lesions had higher proportion of cases with positive p16 immunoexpression (47.4\%) than the malignant cases (37.3\%); however, the difference was not statistically significant. Among the premalignant cases, diffuse positivity (IP score 2) was seen in $44.4 \%$ of OIN III cases as compared to $25 \%$ of OIN II cases and none in OIN I cases (Table 1). Hence, the positivity increased with increase in degree of dysplasia ( $p$ value -0.03 ).

Amongst the various grades of squamous cell carcinoma, maximum proportion of p16 immunoexpression positive cases were found in Poorly differentiated carcinoma (75\%), followed by Moderately differentiated carcinoma (35.5\%) and Well differentiated carcinomas (29.3\%) (Table 2). However, the difference was not statistically significant. To summarize, immunoexpression of p16 was positive maximally in OIN III lesions $(77.8 \%$ overall positivity and $44.4 \%$ diffuse positivity) which was similar to that found in PDSCC cases (75\% overall positivity and $62.5 \%$ diffuse positivity). Regarding p-16 intensity of staining, similar trend was found as p16 IP index. Strong intensity (score 2) was seen in $62.5 \%$ of PDSCC cases followed by $55.6 \%$ of OIN III, $26.8 \%$ of WDSCC cases and $22.6 \%$ of MDSCC cases (Table 2).

p16 immunoexpression did not differ significantly among different age-groups. Female patients showed significantly higher proportion of cases with diffuse p16 immunoexpression positivity ( $43.8 \%$ cases) when compared to proportion of male patients $(17 \%$ cases $)$ ( $\mathrm{p}$ value $=0.045)$.

\begin{tabular}{|c|c|c|c|c|}
\hline \multicolumn{5}{|c|}{ Lesions (n=112) } \\
\hline & $\begin{array}{l}\text { Benign } \\
(n=10) \\
n(\%)\end{array}$ & $\begin{array}{l}\text { Pre- } \\
\text { Malignant } \\
\text { (n=19) } \\
\text { n (\%) }\end{array}$ & $\begin{array}{c}\text { Malignant } \\
\text { (n=83) } \\
\text { n (\%) }\end{array}$ & $\begin{array}{c}\text { Total } \\
(n=112) \\
n(\%)\end{array}$ \\
\hline \multicolumn{5}{|c|}{ p16 IP Score } \\
\hline $0(<10 \%)$ & $\begin{array}{c}10 \\
(100)\end{array}$ & $10(52.6)$ & $52(62.7)$ & $\begin{array}{c}72 \\
(64.3)\end{array}$ \\
\hline $\begin{array}{l}1(10- \\
50 \%)\end{array}$ & $0(0)$ & $4(21)$ & $10(12)$ & $\begin{array}{c}14 \\
(12.5)\end{array}$ \\
\hline $2(>50 \%)$ & $0(0)$ & $5(26.3)$ & $21(25.3)$ & $\begin{array}{c}26 \\
(23.2)\end{array}$ \\
\hline \multicolumn{5}{|c|}{ p16 Intensity Score } \\
\hline 0 (weak) & $\begin{array}{c}10 \\
(100)\end{array}$ & $11(58)$ & $49(59)$ & $\begin{array}{c}70 \\
(62.5) \\
\end{array}$ \\
\hline $\begin{array}{c}1 \\
\text { (moderate) }\end{array}$ & $0(0)$ & $2(10.5)$ & $9(10.8)$ & $11(9.8)$ \\
\hline 2 (strong) & $0(0)$ & $6(31.5)$ & $25(30.1)$ & $\begin{array}{c}31 \\
(27.7)\end{array}$ \\
\hline \multicolumn{5}{|c|}{$\begin{array}{c}\text { Table 1. Distribution of Benign, Premalignant and } \\
\text { Malignant Oral and Oropharyngeal Lesions in Accordance } \\
\text { to p16 Immunoexpression Results }\end{array}$} \\
\hline
\end{tabular}




\begin{tabular}{|c|c|c|c|c|c|c|}
\hline \multicolumn{7}{|c|}{ Lesions $(n=112)$} \\
\hline & \multicolumn{3}{|c|}{ Dysplasia (n=17) } & \multicolumn{3}{|c|}{ SCC $(n=33)$} \\
\hline & $\begin{array}{c}\text { OIN I } \\
(n=3), n(\%)\end{array}$ & $\begin{array}{c}\text { OIN II } \\
(n=6), n(\%)\end{array}$ & $\begin{array}{c}\text { OIN III } \\
(n=8) \text { n (\%) }\end{array}$ & $\begin{array}{c}\text { WDSCC }(n=20), n \\
(\%)\end{array}$ & $\begin{array}{c}\text { MDSCC } \\
(n=11), n \%)\end{array}$ & $\begin{array}{c}\text { PDSCC } \\
(n=7) n(\%)\end{array}$ \\
\hline \multicolumn{7}{|c|}{ p16 IP Score } \\
\hline $0(<10 \%)$ & $5(83.3)$ & $3(75)$ & $2(22.2)$ & $29(70.7)$ & $20(64.5)$ & $2(25)$ \\
\hline $1(10-50 \%)$ & $1(16.7)$ & $0(0)$ & $3(33.3)$ & $4(9.8)$ & $5(16.1)$ & $1(12.5)$ \\
\hline $2(>50 \%)$ & $0(0)$ & $1(25)$ & $4(44.4)$ & $8(19.5)$ & $6(19.4)$ & $5(62.5)$ \\
\hline \multicolumn{7}{|c|}{ p16 Intensity Score } \\
\hline 0 (weak) & $10(100)$ & $3(75)$ & $3(33.3)$ & $27(65.9)$ & $19(61.3)$ & $2(25)$ \\
\hline 1 (moderate) & $0(0)$ & $0(0)$ & $1(11.1)$ & $3(7.3)$ & $5(16.1)$ & $1(12.5)$ \\
\hline 2 (strong) & $0(0)$ & $1(25)$ & $5(55.6)$ & $11(26.8)$ & $7(22.6)$ & $5(62.5)$ \\
\hline Table 2. Dist & & & Malign & 10 & & ce to $p 16$ \\
\hline
\end{tabular}
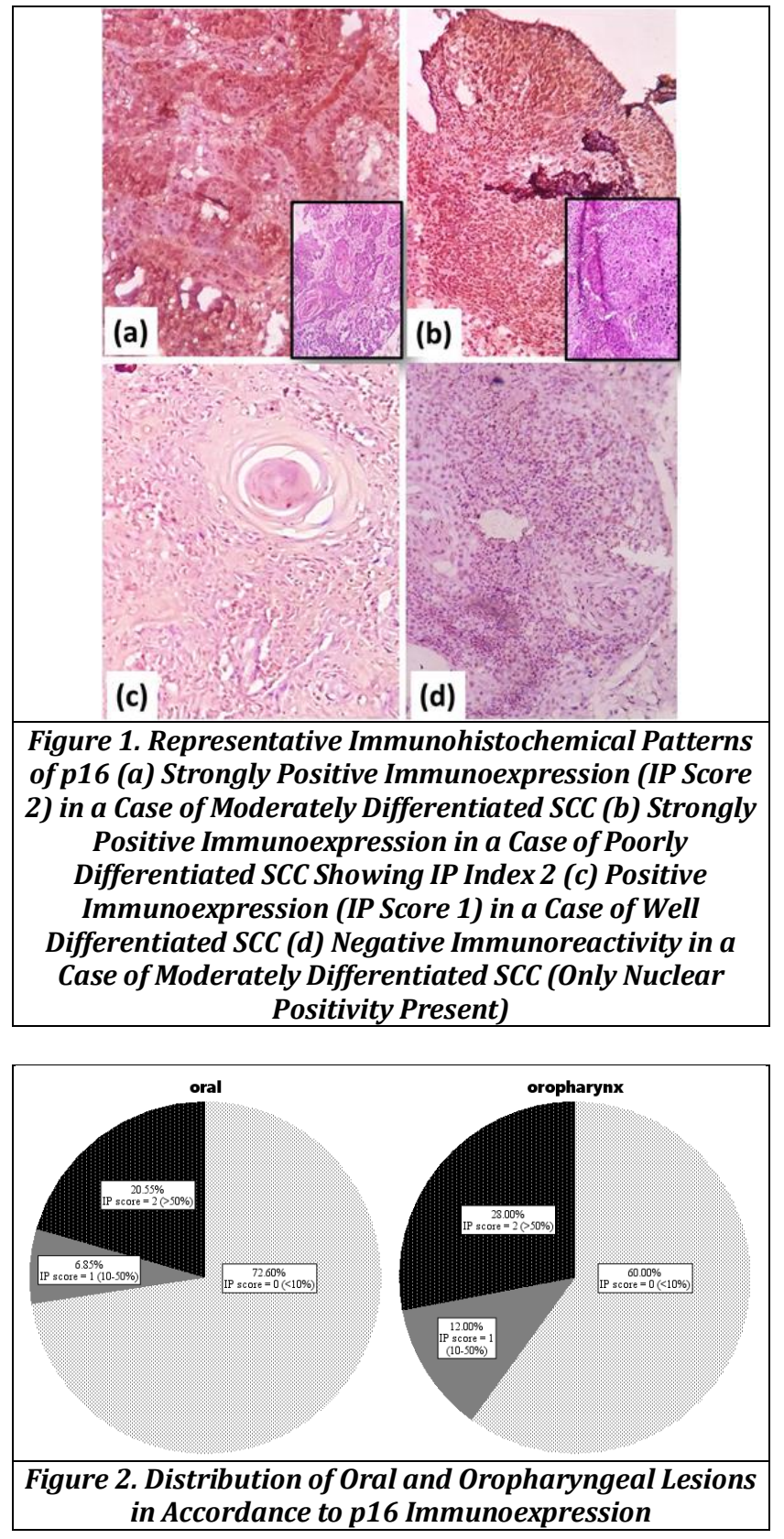

\section{DISCUSSION}

HPV has been recognized as one of the major etiological factor in oral cancer.(18) It has both therapeutic and prognostic significance. HPV-positive oropharyngeal cancers respond well to chemoradiotherapy and are associated with an improved prognosis.(19) For oral cancer, HPV status doesn't have impact on treatment, which is usually surgery, but it might have impact on prognosis.(18) Hence, knowing the HPV status can impact management and patient survival.

High risk HPV infection can be identified in a cell using p16 immunoexpression. The E7 protein of the HPV inhibits the anti-oncogene $\mathrm{Rb}$ which is in turn linked to $\mathrm{p} 16$ through a negative feedback. p16 expression with diffuse positivity in more than $70 \%$ of cells has been suggested as a surrogate marker of active high-risk HPV oncogene expression in oral and oropharyngeal carcinomas.(20-22) Using this criterion, our study points to a prevalence of HPV in oral and oropharyngeal carcinomas to be around $23.2 \%$ in our tertiary care centre. HPV prevalence in squamous cell carcinomas of the oral cavity and oropharynx in India has been reported to be ranging from $15 \%$ to $51 \%(9,23-25)$ and in developed nations highly variable ranging from as low as $10 \%$ to as high as $80 \% \cdot(8,10,26)$ The results of our study correspond well with above studies.

We found increased immunoexpression with increasing grades of dysplasia with OIN I lesions showing positive p16 immunoexpression in only $16.7 \%$ of cases as compared to $25 \%$ in OIN II and $77.8 \%$ in OIN III. Thus, in our study, p16 immunoexpression and pattern correlates with the malignant transformation in oral and oropharyngeal lesions with increased immunoexpression in increasing degrees of dysplasia. However, no significant difference in immunoexpression of p16 was found between different grades of squamous cell carcinomas. Majority of malignant lesions displayed lower p16 immunoexpression than OIN III lesions. Only the Poorly differentiated tumours had high proportion of cases with positive $\mathrm{p} 16$ immunostaining. This is in accordance with literature pointing to HPV-positive oral cancer is usually poorly differentiated nonkeratinizing tumour.(26,27)

Oropharyngeal SCC were found to have higher proportion of positive p16 immunoexpression, and hence HPV positivity, as compared to oral SCC. Previous studies have pointed to this disparity with HPV positivity reaching almost $50 \%$ in oropharyngeal SCC, in particular tonsillar SCC.(8-11) High-risk sexual behaviour has been implicated for placing individuals at higher risk for these HPV-associated oropharyngeal cancers.(12) Additionally, higher proportion of female patients had diffuse p16 positivity than males. Murthy et al.(28) also found a relatively higher incidence of HPV-related SCC in females. This may be attributed to the differences in the pattern of tobacco use in females, patterns of sexual behaviour as p16 positivity is more likely to be detected 
among the non-smokers and those with high-risk sexual behaviours. $(29,30)$

\section{CONCLUSION}

Overall, irrespective of the histological type/grade, $23.2 \%$ of total cases showed diffuse positivity of p16 immunoexpression suggesting the prevalence of HPV in oral and oropharyngeal lesions in our tertiary care center to be approximately $23 \%$. This subset of cases was found to be associated more with poorly differentiated SCC, oropharyngeal lesions and was present in higher proportions in female patients. Such delineation of probable HPV associated oral and oropharyngeal SCC subset can enable effective mobilization of limited HPV screening resources.

\section{ACKNOWLEDGEMENTS}

We are thankful to Dr. Reeni Malik, Prof. and Head Dept. of Pathology GMC, Bhopal for providing general support for the research. Thanks to all the faculty and technical staff of Dept. of Pathology, GMC, Bhopal who provided both technical as well as general support.

\section{REFERENCES}

[1] Ferlay J, Soerjomataram I, Dikshit R, et al. Cancer incidence and mortality worldwide: sources, methods and major patterns in GLOBOCAN 2012. Int J Cancer 2015;136(5):E359-86.

[2] Sankaranarayanan R, Ramadas K, Thomas G, et al. Effect of screening on oral cancer mortality in Kerala, India: a cluster-randomised controlled trial. Lancet 2005;365(9475):1927-33.

[3] Johnson NW, Warnakulasuriya S, Gupta PC, et al. Global oral health inequalities in incidence and outcomes for oral cancer: causes and solutions. Adv Dent Res 2011;23(2):237-46.

[4] Rosai J, Ackerman LV, Rosai J. Rosai and Ackerman's Surgical Pathology. 11 th edn. Edinburgh: Mosby 2011. https://www.goodreads.com/work/best_book/21818 4-rosai-and-ackerman-s-surgical-pathology-2-volumeset-rosai-ackerman-s

[5] Lin WJ, Jiang RS, Wu SH, et al. Smoking, alcohol and betel quid and oral cancer: a prospective cohort study. J Oncol 2011;2011:525976.

[6] Jornet PL, Garcia FJG, Berdugo ML, et al. Mouth selfexamination in a population at risk of oral cancer. Aust Dent J 2015;60(1):59-64.

[7] Cheng YW, Chiou HL, Sheu GT, et al. The association of human papillomavirus 16/18 infection with lung cancer among nonsmoking Taiwanese women. Cancer Res 2001;61(7):2799-803.

[8] Hammarstedt L, Lindquist $D$, Dahlstrand $H$, et al. Human papillomavirus as a risk factor for the increase in incidence of tonsillar cancer. Int J Cancer 2006;119(11):2620-3.

[9] D'Costa J, Saranath D, Dedhia P, et al. Detection of HPV16 genome in human oral cancers and potentially malignant lesions from India. Oral Oncol 1998;34(5):413-20.

[10] Kumaraswamy KL, Vidhya M. Human papilloma virus and oral infections: an update. J Cancer Res Ther 2011;7(2):120-7.
[11] Syrjänen S. HPV infections and tonsillar carcinoma. J Clin Pathol 2004;57(5):449-55.

[12] D'Souza G, Kreimer AR, Viscidi R, et al. Case-control study of human papillomavirus and oropharyngeal cancer. N Engl J Med 2007;356(19):1944-56.

[13] Schache AG, Liloglou T, Risk JM, et al. Evaluation of human papilloma virus diagnostic testing in oropharyngeal squamous cell carcinoma: sensitivity, specificity and prognostic discrimination. Clin Cancer Res 2011;17(19):6262-71.

[14] Agrawal GP, Joshi PS, Agrawal A. Role of HPV-16 in pathogenesis of oral epithelial dysplasia and oral squamous cell carcinoma and correlation of p16INK4A expression in HPV-16 positive cases: an immunohistochemical study. Article ID 807095, International Scholarly Research Notices 2013;2013: p. 7.

[15] Pathak A, Singh M, Agarwal A, et al. Determination of p16 overexpression as an indicator of human papillomavirus infection in oral dysplasia and carcinoma. Indian J Dent Res 2017;28(4):418-23.

[16] Sritippho T, Pongsiriwet S, Lertprasertsuke N, et al. p16 - a possible surrogate marker for high-risk human papillomaviruses in oral cancer? Asian Pac J Cancer Prev 2016;17(8):4049-57.

[17] Dragomir LP, Simionescu C, Mărgăritescu C, et al. P53, p16 and Ki67 immunoexpression in oral squamous carcinomas. Romanian J Morphol Embryol Rev Roum Morphol Embryol 2012;53(1):89-93.

[18] Dayyani F, Etzel CJ, Liu M, et al. Meta-analysis of the impact of human papillomavirus (HPV) on cancer risk and overall survival in head and neck squamous cell carcinomas (HNSCC). Head Neck Oncol 2010;2:15.

[19] Reimers N, Kasper HU, Weissenborn SJ, et al. Combined analysis of HPV-DNA, p16 and EGFR expression to predict prognosis in oropharyngeal cancer. Int J Cancer 2007;120(8):1731-8.

[20] Schache A, Croud J, Robinson M, et al. Human papillomavirus testing in head and neck squamous cell carcinoma: best practice for diagnosis. Methods Mol Biol Clifton NJ 2014;1180:237-55.

[21] Chen ZW, Weinreb I, Kamel-Reid S, et al. Equivocal p16 immunostaining in squamous cell carcinoma of the head and neck: staining patterns are suggestive of HPV status. Head Neck Pathol 2012;6(4):422-9.

[22] El-Naggar AK, Westra WH. p16 expression as a surrogate marker for HPV-related oropharyngeal carcinoma: a guide for interpretative relevance and consistency. Head Neck 2012;34(4):459-61.

[23] Elango KJ, Suresh A, Erode EM, et al. Role of human papilloma virus in oral tongue squamous cell carcinoma. Asian Pac J Cancer Prev 2011;12(4):88996.

[24] Nagpal JK, Patnaik S, Das BR. Prevalence of high-risk human papilloma virus types and its association with P53 codon 72 polymorphism in tobacco addicted oral squamous cell carcinoma (OSCC) patients of Eastern India. Int J Cancer 2002;97(5):649-53. 
[25] Kumar R, Rai AK, Das D, et al. Alcohol and tobacco increases risk of high risk HPV infection in head and neck cancer patients: study from north-east region of India. PLoS One 2015;10(10):e0140700.

[26] Westra WH. The changing face of head and neck cancer in the 21st Century: the impact of HPV on the epidemiology and pathology of oral cancer. Head Neck Pathol 2009;3(1):78-81.

[27] Marur S, D’Souza G, Westra WH, et al. HPV-associated head and neck cancer: a virus-related cancer epidemic. Lancet Oncol 2010;11(8):781-9.
[28] Murthy V, Swain M, Teni T, et al. Human papillomavirus/p16 positive head and neck cancer in India: Prevalence, clinical impact and influence of tobacco use. Indian J Cancer 2016;53(3):387-93.

[29] D’Souza G, Agrawal Y, Halpern J, et al. Oral sexual behaviors associated with prevalent oral human papillomavirus infection. J Infect Dis 2009;199(9):1263-9.

[30] Gillison ML, D’Souza G, Westra W, et al. Distinct risk factor profiles for human papillomavirus type 16positive and human papillomavirus type 16-negative head and neck cancers. J Natl Cancer Inst 2008;100(6):407-20. 